\title{
Bruno Hongre, Jacques Pignault, Dictionnaire du français classique littéraire, De Corneille à Chateaubriand, Préface di Jean Pruvost
}

\section{Monica Pavesio}

\section{(2) OpenEdition \\ Journals}

Edizione digitale

URL: http://journals.openedition.org/studifrancesi/5312

DOI: $10.4000 /$ studifrancesi.5312

ISSN: 2421-5856

\section{Editore}

Rosenberg \& Sellier

\section{Edizione cartacea}

Data di pubblicazione: 1 dicembre 2016

Paginazione: 522

ISSN: 0039-2944

\section{Notizia bibliografica digitale}

Monica Pavesio, « Bruno Hongre, Jacques Pignault, Dictionnaire du français classique littéraire, De Corneille à Chateaubriand, Préface di Jean Pruvost », Studi Francesi [Online], 180 (LX | III) | 2016, online dal 01 janvier 2017, consultato il 18 septembre 2020. URL : http://journals.openedition.org/studifrancesi/ 5312 ; DOI : https://doi.org/10.4000/studifrancesi.5312

Questo documento è stato generato automaticamente il 18 settembre 2020.

\section{cc) (†)}

Studi Francesi è distribuita con Licenza Creative Commons Attribuzione - Non commerciale - Non opere derivate 4.0 Internazionale. 
Bruno Hongre, Jacques Pignault, Dictionnaire du français classique littéraire, De Corneille à Chateaubriand, Préface di Jean Pruvost

Monica Pavesio 


\section{NOTIZIA}

BRUNO HONGRE, JACQUES PIGNAULT, Dictionnaire du français classique littéraire, De Corneille à Chateaubriand, Préface di Jean Pruvost, Paris, Champion Classiques, 2015, 770 pp.

1 Nel leggere le opere classiche, gli studenti e i lettori possono essere ostacolati dalla presenza di parole non più in uso o impiegate con un significato diverso da quello odierno. Esistono numerosi dizionari specialistici sulla lingua del XVII e del XVIII secolo, ma nessuno ancora su quella che i curatori del Dictionnaire chiamano "il francese classico letterario", ossia la lingua francese che nasce con Corneille e si sviluppa fino a Chateaubriand, comprendendo due secoli.

2 Come sottolinea Jean Pruvost nella prefazione, la lingua francese ha, ovviamente, subito un'evoluzione in questi due secoli ma, grazie al suo insegnamento nelle scuole, il francese di Corneille, Molière e Racine è diventato un modello da imitare e da diffondere. E sarà Chateaubriand, nato nel 1768, nel cuore del XVIII secolo, a chiudere il cerchio, utilizzando una lingua fine, ampia e maestosa, ormai definita classica.

Il Dictionnaire du français classique littéraire non si ferma alla semplice informazione linguistica data dall'etimologia del nome, dalle sue definizioni e da una lista di citazioni, ma ne descrive anche il substrato filosofico veicolato dalla lingua classica letteraria. Uno strumento utile, se non necessario, che facilita la comprensione del francese del XVII e XVIII secolo e di conseguenza la lettura delle opere letterarie di questo periodo. 